\title{
Spatial and temporal variation in reef fish assemblages of marine parks in New South Wales, Australia - baited video observations
}

\author{
Hamish A. Malcolm ${ }^{1,5, *}$, William Gladstone ${ }^{2}$, Steven Lindfield ${ }^{2}$, James Wraith ${ }^{3}$, \\ Tim P. Lynch ${ }^{4}$ \\ ${ }^{1}$ Solitary Islands Marine Park, NSW Marine Parks Authority, PO Box J297 Coffs Harbour Jetty, New South Wales 2450, Australia \\ ${ }^{2}$ School of Environmental and Life Sciences, University of Newcastle (Ourimbah Campus), PO Box 127, Ourimbah, \\ New South Wales 2258, Australia \\ ${ }^{3}$ School of Biological Sciences, University of Wollongong, Northfields Ave., Wollongong, New South Wales 2522, Australia \\ ${ }^{4}$ Jervis Bay Marine Park, PO Box 89, Huskisson, New South Wales 2540, Australia \\ ${ }^{5}$ National Marine Science Centre, University of New England, PO Box J321 Coffs Harbour Jetty, New South Wales 2450, Australia
}

\begin{abstract}
Baited remote underwater video stations (BRUVS) were used to examine variation in assemblages of reef fishes at scales of 100s of kilometres (between 3 marine parks in New South Wales, Australia) and kilometres (between 4 sites within each park). Temporal variation over 5 yr was also examined in 1 park (Solitary Islands). BRUVS were able to sample the relative abundance and distribution of species from a wide range of trophic groups, and were particularly effective for detecting cryptic predators. Significant variability in the fish assemblages occurred between each park consistent with the latitudinal distribution of the parks. Fish assemblages also varied significantly between sites within each park. Contrary to expectations, total species richness did not follow the expected latitudinal gradient. However, observed geographical patterns in species richness of certain families such as Labridae (greater richness in the most northern park) and Monacanthidae (greater species richness in southern parks) followed expectations. Abundant schooling species, common to all 3 parks, were important contributors to variation between sites. Temporal variation over 5 yr at 1 park was relatively minor compared to the spatial variation among the 3 parks. This suggests largescale spatial separation is more important for structuring fish assemblages than time. A network of marine parks will therefore be required to represent variation in reef fish assemblages over this latitudinal scale.
\end{abstract}

KEY WORDS: Baited remote underwater video stations $\cdot$ BRUVS $\cdot$ Marine protected area $\cdot$ Reef fish assemblage $\cdot$ Representativeness $\cdot$ Spatial patterns

Resale or republication not permitted without written consent of the publisher

\section{INTRODUCTION}

Reef fishes are an important component of marine biodiversity and include species that provide both top-down control of reef ecosystems through trophic cascades (Babcock et al. 1999) and the biomass of recreational and commercial fisheries (Henry \& Lyle 2003). Understanding the distribution of reef fish assemblages at a range of spatial scales is a critical step towards identifying important underlying ecological factors and processes (Under- wood et al. 2000). This knowledge is also necessary for the selection and design of marine protected areas (MPAs) that aim to be comprehensive, adequate and representative (CAR) in their conservation of reef fishes (Lubchenco et al. 2003, Gladstone 2007).

Application of the CAR principles relies on suitable data being available on the distribution and abundance of biodiversity. However, the majority of our understanding of spatial variation in reef fish assemblages is based on either diver-based underwater 
visual census (UVC) surveys in shallow water $(<15 \mathrm{~m})$ (Barrett 1995, Edgar \& Barrett 1999, Anderson \& Millar 2004) or capture methods such as trapping (Cappo \& Brown 1996). The relative paucity of studies at depths $>15 \mathrm{~m}$ is a result of logistical constraints (such as those associated with no-decompression diving limits), selective constraints due to fishing gear biases, or sampling constraints such as topographically complex environments that make trawl sampling impractical.

The use of baited remote underwater video stations (BRUVS) (Cappo et al. 2003, 2004) provides a logistically feasible alternative or complementary method to UVC that can be used at various depths and in topographically complex habitats. Similar to sampling methods used to capture reef fishes, such as angling and trapping, BRUVS are biased toward species attracted to baits (Willis et al. 2000). However, this bias may be advantageous for conservation and fisheries management purposes as it provides information on species that are targeted or caught as by-catch with baits. In particular, BRUVS are able to detect rarer large predatory fish and shy cryptic species with less sampling effort than diver transects or unbaited video stations (Watson et al. 2005). Baited video techniques have been successfully used for a variety of applications along the continental shelf, such as monitoring the recovery of fishes in MPAs (Westera et al. 2003, Willis et al. 2003), indexing abundance of commercially important juvenile fish compared to long line catch per unit effort (Ellis \& DeMartini 1995), comparing fish assemblages over large spatial scales (Stobart et al. 2007) and as a non-destructive alternative for describing spatial groupings of fish assemblages on commercial trawl grounds (Cappo et al. 2004). The non-destructive nature of BRUVS is especially important for studies located in MPAs, where conservation is the priority.

Conservation planning in MPAs occurs at a hierarchy of nested spatial scales (Margules \& Pressey 2000, Ferrier 2002). For example, the selection of several large MPAs that aim to conserve biodiversity across several bioregions requires information at a spatial scale of 100s of kilometres. The zoning of individual multipleuse MPAs (e.g. into areas where extraction is allowed or prohibited) requires biodiversity data at scales of kilometres to 10s of kilometres, or smaller (ANZECC TFMPA 1998). Given their previously mentioned advantages, BRUVS have significant potential as a sampling technique to compare reef fish assemblages for conservation planning at multiple scales. However, comparing samples from single points in time can potentially lead to erroneous conclusions due to differences associated with temporal variability (Stobart et al. 2007). The stability of assemblage patterns over years has not been reported in previous BRUVS studies in the literature and therefore requires examination.
The broad aim of the present study was to compare reef fish assemblages using BRUVS below depths suitable for UVC methods, at scales useful to marine park planning, and to examine the potential for these patterns to persist over years. The specific objectives were: (1) to assess the assemblage of scavengers and other species of reef fishes sampled by this technique on rocky reefs in depths of 15 to $30 \mathrm{~m}$, (2) to describe the spatial structure of reef fish assemblages by comparing reef fish assemblages between 3 marine parks (separated by 100s of kilometres) and between sites within each park (separated by kilometres), and (3) to test the temporal stability of fish assemblages over $5 \mathrm{yr}$ at 1 marine park using these methods.

In New South Wales (NSW), on the eastern coast of Australia, a network of MPAs has been established across 3 of the 5 bioregions that span the NSW coastline (NSW Marine Parks Authority 2006). Given that bioregions delineate areas with different ecological characteristics (ANZECC TFMPA 1999), differences in reef fish assemblages between marine parks were expected at this scale. We also expected that species richness of fishes would decline southward given the latitudinal gradient of Australia's east coast (Jablonski \& Sepkoski 1996).

\section{MATERIALS AND METHODS}

Study areas and sampling design. Six large multiple-use marine parks have been established as part of a network of MPAs in NSW. This includes Solitary Islands Marine Park (SIMP), Port Stephens-Great Lakes Marine Park (PSGLMP) and Jervis Bay Marine Park (JBMP), which are spaced over $5^{\circ}$ of latitude (Fig. 1). Each of these marine parks is separated by at least $300 \mathrm{~km}$ and is judged to be in a different bioregion (ANZECC TFMPA 1999).

Sampling occurred in these 3 marine parks, at 4 sites within each park that were separated by 2 to $20 \mathrm{~km}$ (Fig. 1). Eight replicate BRUVS were set in each site (i.e. $\mathrm{n}=32$ replicates park ${ }^{-1}$ ). Within each site we haphazardly sampled rocky reef in depths of 15 to $30 \mathrm{~m}$. Multiple ( 3 or 4 ) BRUVS were deployed within 5 to $10 \mathrm{~min}$ of each other. With limited knowledge of the response of a broad suite of species to a bait plume, a minimum distance of $200 \mathrm{~m}$ was kept between replicates to attempt to maintain a level of independence. Each video was deployed for $30 \mathrm{~min}$, and only those with a full field of view were retained for analysis. Colour depth sounders were used to select reef habitat in the required depth range, and the distances between replicates were determined with global positioning systems (GPS). The JBMP sites were sampled in 2005; PSGLMP, in 2006; and SIMP sites, in 2002 to 2006. Sam- 


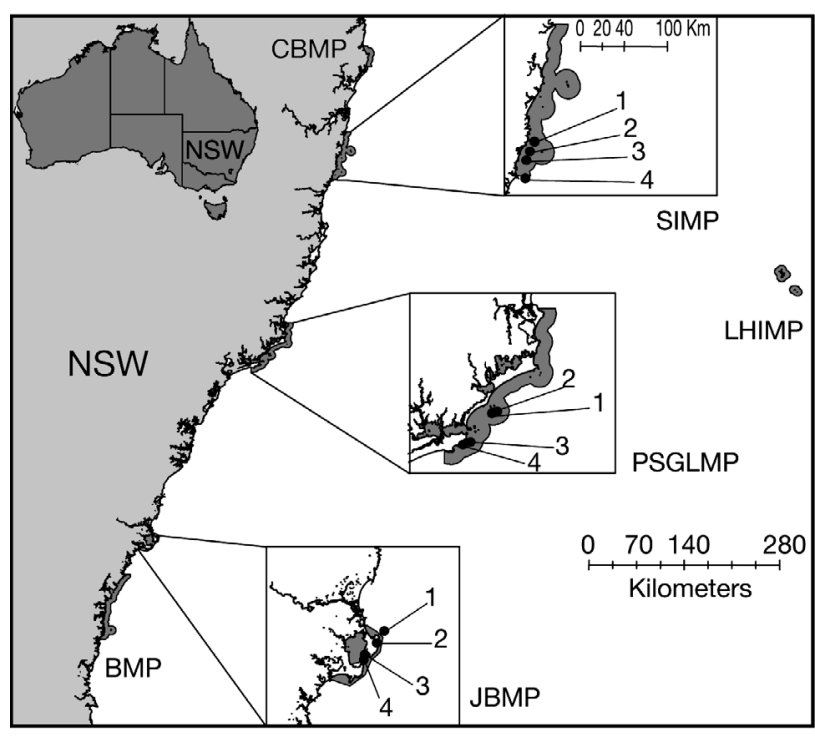

Fig. 1. Marine parks in New South Wales (NSW), Australia, showing sampling sites (1 to 4 ) at the Solitary Islands Marine Park (SIMP), Port Stephens-Great Lakes Marine Park (PSGLMP) and Jervis Bay Marine Park (JBMP). Other marine parks in NSW are: Cape Byron Marine Park (CBMP), Lord Howe Island Marine Park (LHIMP) and Batemans Marine Park (BMP)

pling at each park was conducted between July and November (austral winter to spring), with sampling conducted in SIMP during July to August for all $5 \mathrm{yr}$. Two of the sites in SIMP were within a 'sanctuary zone' where fishing is not permitted; this zoning was established in 2002.

The BRUVS system. Each BRUVS consisted of a video-camera in an underwater housing, an attachment frame, a bait-pole with bait, and a rope and float system linking the BRUVS to the surface. We used pilchard Sardinops neopilchardus baits to attract fish to a viewing area in front of each camera. The baits were mashed into a plastic mesh bait bag and attached to the end of a bait-pole at a distance of $1.5 \mathrm{~m}$ from each camera. The cameras were all similar digital handycams with wide-angle lenses. The housings were made from high-density polyethylene pipe with flat acrylic end-ports. Each housing and bait-pole was bolted to the steel frame so that fish could be viewed in a horizontal orientation to the benthos. Our field of view was standardised to a distance of approximately $2 \mathrm{~m}$ estimated behind the bait, to minimise the effects of water visibility on our measure of relative abundance. This field of view represents a volume of $9.4 \mathrm{~m}^{3}$ (M. Coram \& W. Gladstone unpubl. data). As the counts reflect relative abundance and not density, the data were expected to be robust to variability between observers in estimating this field of view.

Analysis of video-tapes. Video-tapes were reviewed on a standard television screen connected to a video camera. The identity of each fish species and an index of its relative abundance (MaxN) were recorded. MaxN was the maximum number of individual fish of each species in the frame at any 1 time during the 30 min video record. This eliminated the chance of recounting the same fish. Species accumulation curves for each park were used to determine sampling adequacy (EstimateS software, Colwell 2005).

Multivariate analyses. Non-metric multidimensional scaling (nMDS) ordination, based on a Bray-Curtis dissimilarity matrix of fourth-root transformed data, was used to visually depict variation in assemblage structure (Clarke 1993) (PRIMER software, Plymouth Marine Laboratories). Centroids of the assemblage at each site were displayed on the nMDS ordination because of the large number of replicate samples (Anderson 2001), and determined using PCO software (Anderson 2003). Distancebased permutational multivariate analysis of variance (PERMANOVA) was used to test the null hypothesis of no difference in assemblage structure between parks and between sites nested within parks using PERMANOVA software (Anderson 2005). The factor Park was analysed as an orthogonal, fixed factor with 3 levels (SIMP, PSGLMP, JBMP), while the factor Site was analysed as a random factor with 4 levels nested in each park. The PERMANOVA test for differences in assemblage structure between years and sites in SIMP treated years as an orthogonal, fixed factor with 5 levels (2002 to 2006) and sites as a random factor with 4 levels.

Species responsible for dissimilarity in the assemblage structure of fishes were determined with the similarity percentages routine (SIMPER) in PRIMER. We considered that large values (i.e. $>1$ ) of the ratio of $\bar{\delta}_{i} / \mathrm{SD}\left(\bar{\delta}_{i}\right)$ for a species (where $\bar{\delta}_{i}$ is the average contribution of the $i$ th species to the overall dissimilarity $[\bar{\delta}]$ between 2 groups and SD is standard deviation) indicated the species was consistently important to dissimilarity in all pairwise comparisons of samples in 2 groups (Clarke 1993). We considered species with $\% \bar{\delta}_{i}>$ $3 \%$ and with $\bar{\delta}_{i} / \mathrm{SD}\left(\bar{\delta}_{i}\right)>1$ as being important contributors to dissimilarity between parks (Terlizzi et al. 2005).

Univariate analyses. The null hypothesis of no difference in abundance between parks and between sites (parks) was tested with 2-factor analysis of variance (ANOVA) (GMAV software, Institute of Marine Ecology, University of Sydney). The variables tested were relative abundance (mean MaxN) for those species determined by SIMPER analysis as being important contributors to differences between parks in assemblage structure. Prior to ANOVA analysis, the assumption of homogeneity of variance was tested by Cochran's test (Underwood 1981). Where necessary, data were $\ln (x+1)$ transformed to homogenise variances. When this transformation was unsuccessful, the raw data were analysed, as ANOVA is robust to depar- 
tures from this assumption for the sample sizes used in our study (Underwood 1997).

A 2-factor ANOVA was used to examine potential differences between years and sites within SIMP for any species determined by SIMPER analysis as being important contributors to differences (i.e. $\% \bar{\delta}_{i}>3 \%$ and $\left.\bar{\delta}_{i} / \operatorname{SD}\left(\bar{\delta}_{i}\right)>1\right)$. Potential differences between years and sites in SIMP due to marine park zoning were also explored for Pagrus auratus, given the findings of other studies for this species (Willis et al. 2003).

\section{RESULTS}

\section{Reef fish assemblage}

A total of 101 species (44 families) were observed from SIMP (2006 data), PSGLMP and JBMP combined, representing 11 species (9 families) of Chondrichthyes and 90 species (35 families) of Osteichthyes, from various trophic groups including predators, herbivores and planktivores (Appendix 1). The fish family that was most speciose in our samples was Labridae (19 species). The Chondrichthyes sampled included 8 species of sharks and 3 species of rays. Species were accumulated at a similar rate, with increasing replication in each park, although accumulation curves did not reach an asymptote for any park (Fig. 2).

A total of 5874 individual fish was observed by combining MaxN data from all sets. The most abundant species were the schooling planktivores Atypichthys strigatus (Scorpididae, 1280 ind.), Scorpis lineolata (Scorpididae, 1137 ind.), Trachurus novaezelandiae (Carangidae, 971 ind.) and the predator Ophthalmolepis lineolatus (Labridae, 323 ind.). Twenty-seven species were observed only as single ind. (SIMP 9 species, PSGLMP 8 species, JBMP 10 species).

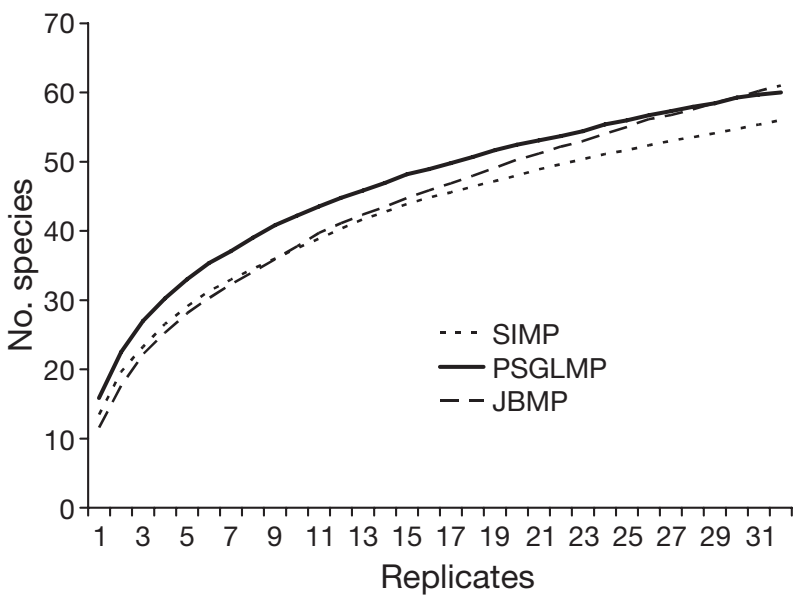

Fig. 2. Mean species accumulation curves for each park based on 1000 random selections (without replacement) of replicate samples. Park abbreviations: see Fig. 1

\section{Spatial variation in assemblages between and within parks}

Separation of parks on the nMDS ordination was consistent with their latitudinal distribution (Fig. 3). The fish assemblages of each park were significantly different (Table 1). The greatest dissimilarity in assemblage structure occurred between the most northern (SIMP) and southern (JBMP) parks. PSGLMP, located approximately midway between SIMP and JBMP, was equally dissimilar to both (Table 1). Fish assemblages also differed significantly between most sites within each park (Fig. 3, Table 1).

Table 1. Summary of results of permutational multivariate analysis of variance (PERMANOVA) showing the significance of differences in assemblage structure between parks and between sites (parks), average dissimilarity between parks and post hoc pairwise comparisons of parks. Park abbreviations: see Fig. 1

\begin{tabular}{|c|c|c|c|c|}
\hline \multicolumn{4}{|c|}{ PERMANOVA results parks } & $\mathrm{p}$ \\
\hline Park & 2 & 22245.64 & 6.17 & 0.0008 \\
\hline Site (Park) & 9 & 3603.20 & 3.21 & 0.0002 \\
\hline Residual & 84 & 1121.23 & & \\
\hline \multicolumn{5}{|c|}{ Average dissimilarity within/between parks } \\
\hline Park & SIMP & PSGLMP & JBMP & \\
\hline SIMP & 29.86 & & & \\
\hline PSGLMP & 43.16 & 24.20 & & \\
\hline JBMP & 51.41 & 40.04 & 33.51 & \\
\hline \multicolumn{5}{|c|}{ Post hoc comparison of parks } \\
\hline Comparison & $t$ & $\mathrm{p}$ & & \\
\hline SIMP vs. PSGLMP & 2.61 & 0.03 & & \\
\hline SIMP vs. JBMP & 2.72 & 0.03 & & \\
\hline PSGLMP vs. JBMP & 2.06 & 0.03 & & \\
\hline
\end{tabular}

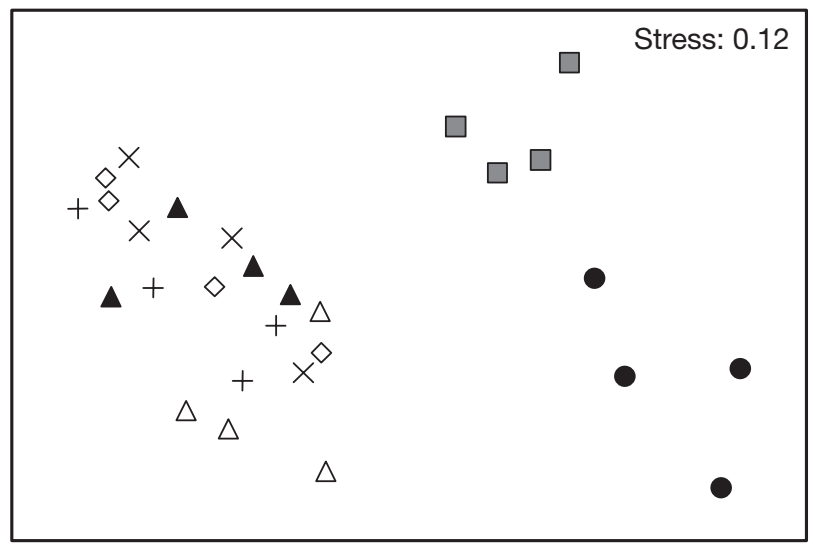

Fig. 3. nMDS plot, based on centroids of 4 sites within each park («: Solitary Islands Marine Park, 2006; $\square$ : Port StephensGreat Lakes Marine Park; @: Jervis Bay Marine Park) and previous yearly data for SIMP $(+: 2002 ; \times: 2003 ; \diamond: 2004 ; \Delta: 2005)$ 
Similar numbers of total species were recorded in SIMP (56 species), PSGLMP (60 species) and JBMP (60 species). More sharks and rays were recorded in PSGLMP (10 species) than in either SIMP in 2006 (5 species) or JBMP (5 species), or even SIMP over $5 \mathrm{yr}$ (9 species). More species of Labridae were recorded in SIMP (14 species) than JBMP (10 species) or PSGLMP (4 species). More species of Monacanthidae were recorded in PSGLMP (8 species) and JBMP ( 7 species) than in SIMP (2 species).

SIMPER identified 13 species as being influential in differentiating the fish assemblages of the 3 parks (Table 2). Variation in the abundance of the common schooling species Atypichthys strigatus and Scorpis lineolata meant that they were consistently influential. Another common schooling species, Trachurus novaezelandiae, was an important contributor to all pairwise differences in assemblage structure and occurred in greatest numbers in PSGLMP. The girdled parma Parma unifasciata (Pomacentridae) was abundant only in SIMP, whereas the Port Jackson shark Heterodontus portusjacksoni (Heterodontidae) was not recorded in SIMP and differed in abundance between PSGLMP (average MaxN = 1.28) and JBMP (0.72). The snapper Pagrus auratus (Sparidae) was present, but varied in abundance in all parks (SIMP mean $\operatorname{MaxN}=1.53$, PSGLMP $=2.19, \mathrm{JBMP}=0.41$.

\section{Spatial variation in species between and within parks}

Seven of the 13 species identified as being influential in differentiating the assemblages, differed at the park level, but not the site level (Fig. 4, Table 3). The relative abundance (mean MaxN) of Scorpaena cardinalis (Scorpaenidae) and Parma unifasciata decreased strongly with increasing latitude, with the latter not recorded at JBMP. Parma microlepis was only recorded
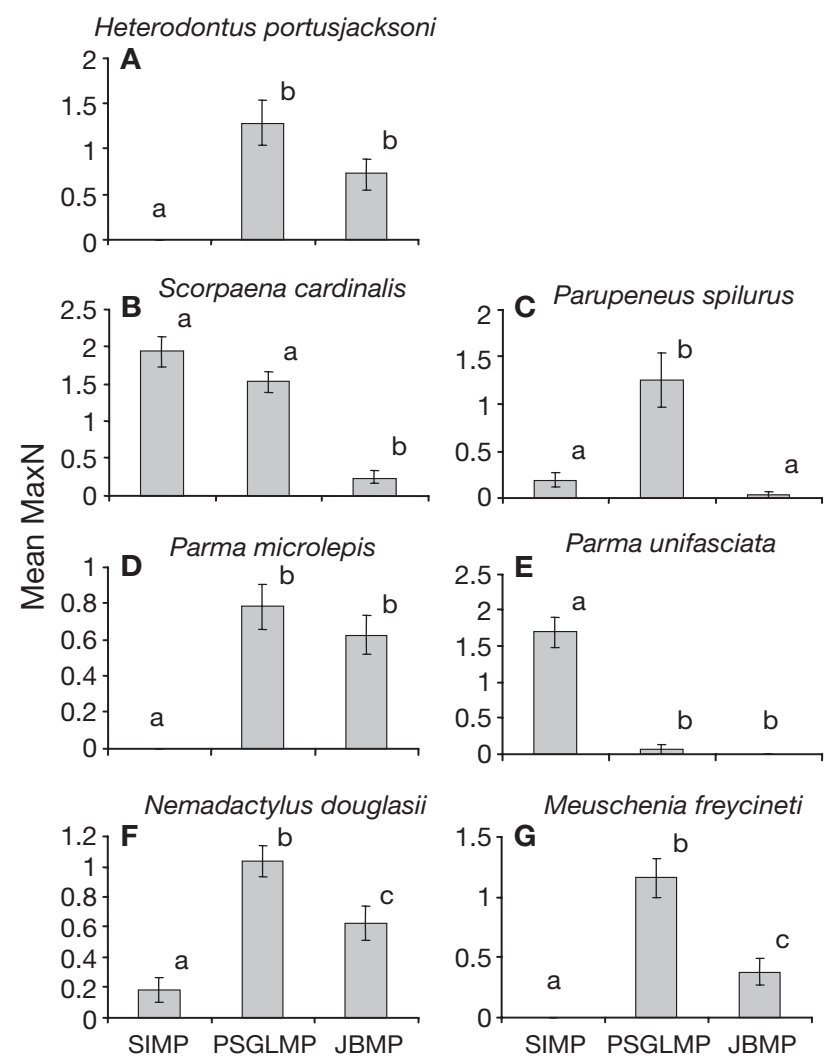

Fig. 4. Mean MaxN $( \pm \mathrm{SE})$ for 7 species that differed significantly in abundance only between parks. Parks sharing the same letter above bars did not significantly differ in mean MaxN (by Student-Newman-Keuls test)

at the southern parks, and found at both of these in similar abundances. The average number of Heterodontus portusjacksoni (Heterodontidae), Nemadactylus douglasii (Cheilodactylidae) and Meuschenia freycineti (Monacanthidae) differed between all 3 parks; all were found in greatest numbers at PSGLMP, followed by JBMP, then SIMP.

Table 2. Overall dissimilarity $(\bar{\delta})$ in fish assemblages between parks (SIMPER). Species regarded as being important contributors to the assemblage dissimilarity are shown in bold. Values shown for each park in the pairwise comparisons are the average MaxN for the species. Park abbreviations: see Fig. 1

\begin{tabular}{|c|c|c|c|c|c|c|c|c|c|}
\hline \multirow{2}{*}{ Taxon } & \multicolumn{3}{|c|}{ SIMP vs. PSGLMP } & \multicolumn{3}{|c|}{ SIMP vs. JBMP } & \multicolumn{3}{|c|}{ PSGLMP_vs. JBMP } \\
\hline & $\bar{\delta}_{i}$ & $\% \bar{\delta}_{i}$ & $\bar{\delta}_{i} / \mathrm{SD}\left(\bar{\delta}_{i}\right)$ & $\bar{\delta}_{i}$ & $\% \bar{\delta}_{i}$ & $\bar{\delta}_{i} / \mathrm{SD}\left(\bar{\delta}_{i}\right)$ & $\bar{\delta}_{i}$ & $\% \bar{\delta}_{i}$ & $\bar{\delta}_{i} / \mathrm{SD}\left(\bar{\delta}_{i}\right)$ \\
\hline Atypichthys strigatus & 3.30 & 5.60 & 1.23 & 4.04 & 5.86 & 1.43 & 3.28 & 5.53 & 1.37 \\
\hline Parma unifasciata & 2.84 & 4.82 & 2.51 & 3.54 & 5.13 & 2.50 & 0.10 & 0.17 & 0.18 \\
\hline Trachurus novaezelandiae & 2.79 & 4.73 & 0.89 & 3.37 & 4.89 & 1.05 & 3.50 & 5.90 & 1.13 \\
\hline Meuschenia freycineti & 2.40 & 4.07 & 1.77 & 1.09 & 1.58 & 0.66 & 2.08 & 3.50 & 1.26 \\
\hline Scorpis lineolata & 2.26 & 3.84 & 1.27 & 2.65 & 3.84 & 1.11 & 2.09 & 3.53 & 1.12 \\
\hline Nemadactylus douglasii & 2.24 & 3.81 & 1.75 & 1.85 & 2.69 & 1.06 & 1.58 & 2.67 & 0.95 \\
\hline Heterodontus portusjacksoni & 2.13 & 3.61 & 1.32 & 1.84 & 2.68 & 0.89 & 1.90 & 3.20 & 1.13 \\
\hline Parma microlepis & 1.85 & 3.14 & 1.26 & 1.77 & 2.57 & 1.03 & 1.64 & 2.76 & 1.02 \\
\hline Aulopus purpurissatus & 1.83 & 3.11 & 1.22 & 1.33 & 1.94 & 0.77 & 2.11 & 3.56 & 1.30 \\
\hline Pagrus auratus & 1.82 & 3.08 & 1.13 & 2.42 & 3.51 & 1.16 & 2.66 & 4.48 & 1.49 \\
\hline Parupeneus spilurus & 1.79 & 3.04 & 1.08 & 0.60 & 0.88 & 0.46 & 1.94 & 3.28 & 1.06 \\
\hline Scorpaena cardinalis & 0.77 & 1.31 & 0.75 & 3.30 & 4.79 & 1.80 & 2.60 & 4.38 & 1.68 \\
\hline Notolabrus gymnogenis & 0.52 & 0.88 & 0.63 & 2.83 & 4.11 & 1.48 & 2.52 & 4.26 & 1.54 \\
\hline
\end{tabular}


Table 3. Summary of results of 2-factor ANOVA testing for differences in MaxN of 13 species between parks and between sites within parks. ${ }^{*}$ Cochran's test $p>0.05$

\begin{tabular}{|c|c|c|c|c|}
\hline Source & df & MS & $F$ & $\mathrm{p}$ \\
\hline \multicolumn{5}{|c|}{ Meuschenia freycineti ${ }^{\mathrm{a}}$} \\
\hline Park & 2 & 3.81 & 79.45 & $<0.001$ \\
\hline Site (Park) & 3 & 0.05 & 0.41 & 0.93 \\
\hline Residual & 84 & 0.12 & & \\
\hline \multicolumn{5}{|c|}{ Parupeneus spilurus $^{\mathrm{b}}$} \\
\hline Park & 2 & 14.07 & 64.33 & $<0.001$ \\
\hline Site (Park) & 9 & 0.22 & 0.20 & 0.99 \\
\hline Residual & 84 & 1.07 & & \\
\hline \multicolumn{5}{|c|}{ Parma unifasciata $^{\mathrm{b}}$} \\
\hline Park & 2 & 29.29 & 55.50 & $<0.001$ \\
\hline Site (Park) & 9 & 0.53 & 0.96 & 0.48 \\
\hline Residual & 84 & 0.55 & & \\
\hline \multicolumn{5}{|c|}{ Scorpaena cardinalis ${ }^{\mathrm{a}}$} \\
\hline Park & 2 & 6.55 & 47.99 & $<0.001$ \\
\hline Site (Park) & 9 & 0.14 & 1.06 & 0.40 \\
\hline Residual & 84 & 0.13 & & \\
\hline \multicolumn{5}{|c|}{ Nemadactylus douglasi $^{\mathrm{c}}$} \\
\hline Park & 2 & 5.70 & 26.05 & $<0.001$ \\
\hline Site (Park) & 9 & 0.22 & 0.67 & 0.73 \\
\hline Residual & 84 & 0.33 & & \\
\hline \multicolumn{5}{|c|}{ Notolabrus gymnogenis $^{\mathrm{a}}$} \\
\hline Park & 2 & 5.07 & 23.36 & $<0.001$ \\
\hline Site (Park) & 9 & 0.23 & 2.84 & 0.006 \\
\hline Residual & 84 & 0.08 & & \\
\hline \multicolumn{5}{|c|}{ Parma microlepis ${ }^{\mathrm{c}}$} \\
\hline Park & 2 & 5.47 & 21.00 & $<0.001$ \\
\hline Site (Park) & 9 & 0.26 & 0.89 & 0.54 \\
\hline Residual & 84 & 0.29 & & \\
\hline \multicolumn{5}{|c|}{ Heterodontus portusjacksoni ${ }^{a}$} \\
\hline Park & 2 & 3.59 & 17.49 & 0.001 \\
\hline Site (Park) & 9 & 0.21 & 1.09 & 0.38 \\
\hline Residual & 84 & 0.19 & & \\
\hline \multicolumn{5}{|c|}{ Aulopus purpurissatus ${ }^{\mathrm{C}}$} \\
\hline Park & 2 & 5.79 & 4.69 & 0.04 \\
\hline Site (Park) & 9 & 1.24 & 4.11 & $<0.001$ \\
\hline Residual & 84 & 0.30 & & \\
\hline \multicolumn{5}{|c|}{ Trachurus novaezelandiae $^{\mathrm{a}}$} \\
\hline Park & 2 & 8.80 & 0.73 & 0.51 \\
\hline Site (Park) & 9 & 12.04 & 13.70 & $<0.001$ \\
\hline Residual & 84 & 0.88 & & \\
\hline \multicolumn{5}{|c|}{ Pagrus auratus $^{\text {a }}$} \\
\hline Park & 2 & 4.76 & 4.19 & 0.05 \\
\hline Site (Park) & 9 & 1.14 & 4.48 & $<0.001$ \\
\hline Residual & 84 & 0.25 & & \\
\hline \multicolumn{5}{|c|}{ Scorpis lineolate ${ }^{b}$} \\
\hline Park & 2 & 135.88 & 0.13 & 0.88 \\
\hline Site (Park) & 9 & 1059.31 & 4.46 & $<0.001$ \\
\hline Residual & 84 & 237.63 & & \\
\hline \multicolumn{5}{|c|}{ Atypichthys strigatus } \\
\hline Park & 2 & 2.34 & 0.40 & 0.68 \\
\hline Site (Park) & 9 & 5.88 & 3.51 & 0.001 \\
\hline Residual & 84 & 1.67 & & \\
\hline $\begin{array}{l}{ }^{\mathrm{a}} \ln (x+1) \text { tran } \\
{ }^{\mathrm{b}} \text { Untransform } \\
{ }^{\mathrm{c}} \text { Untransform }\end{array}$ & $\begin{array}{l}\text { iance } \\
\text { s het } \\
\text { s hon }\end{array}$ & $\begin{array}{l}\text { s homoge } \\
\text { erogeneou } \\
\text { logeneous }\end{array}$ & $\begin{array}{l}\text { heous } \\
\mathrm{s}^{*}\end{array}$ & \\
\hline
\end{tabular}

The relative abundances of 4 species varied significantly among sites, but did not differ among parks (Fig. 5A to D, Table 3). These included the 3 mostabundant species, Trachurus novaezelandiae, Scorpis lineolata and Atypichthys strigatus. These schooling planktivores, along with Pagrus auratus, showed strong site differences at all parks, the exception of $S$. lineolata at PSGLMP. Two species, Notolabrus gymnogenis (Labridae) and Aulopus purpurissatus (Aulopidae), differed at both the park and site levels (Fig. 5E,F, Table 3).

\section{Temporal stability of fish assemblages in SIMP}

A total of 88 species were recorded from 180 replicates in the SIMP from 2002 to 2006 ( $\mathrm{n}=36$ replicates $\left.\mathrm{yr}^{-1}\right)$. The total number of species recorded in each year was similar, with the average number of species per site per year ranging from $30.7( \pm 2.1 \mathrm{SE})$ to 32.5 $( \pm 1.3 \mathrm{SE})$. Individually, sites were more variable through time, with 1 site having a range of 9 species over the course of the study (Site 3: 25 species in 2004, 34 in 2006). The overall range from all sites for all years was 25 to 37 species. The number of additional species recorded in each subsequent year decreased from 13 in 2003 to 6 in 2006. The most speciose family recorded was Labridae. The number of labrid species was similar in all years (13 or 14 species), except for 2005 (9 species).
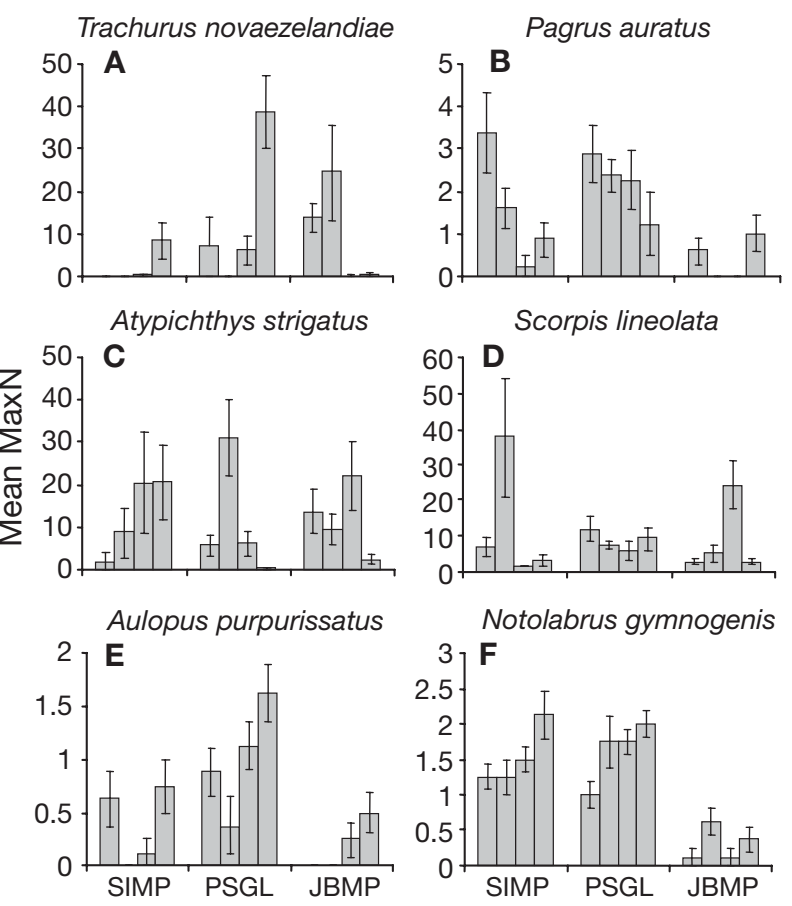

Fig. 5. Mean MaxN $( \pm \mathrm{SE})$ at each site for 6 species that differed significantly in abundance between sites within parks 
Eight species of Osteichthyes were recorded at all 4 sites in all 5 yr (Appendix 1). These included Notolabrus gymnogenis and Ophthalmolepis lineolatus (Labridae), Gymnothorax prasinus (Muraenidae), Parma unifasciata (Pomacentridae), Hypoplectrodes maccullochi (Serranidae), Scorpaena cardinalis (Scorpaenidae) and Pagrus auratus (Sparidae). Three species, O. lineolatus, N. gymnogenis and P. unifasciata, were recorded in 90,87 and $83 \%$ of replicate sets, respectively. A number of other species were present at most sites in most years, including 2 Chondrichthyans, the blind shark Brachaelurus waddi (Brachaeluridae) and the ornate wobbegong Orectolobus ornatus (Orectolobidae). The 2 species that were numerically dominant, Scorpis lineolata and Atypichthys strigatus, were recorded at most sites in each year, but were patchy in their abundance between replicate sets within a site. Overall, there was a relatively stable assemblage of about 30 species within the total of 88 species observed. The remaining species included 17 that were incidentally recorded once, and 7 only that were recorded twice.

There was temporal stability in assemblages at the broad geographic or latitudinal scale, as SIMP was separated from the other parks on the nMDS ordination over the $5 \mathrm{yr}$ studied, including years when surveys were undertaken in the other parks (Fig. 3). There were changes over time at the within-park scale, and these were not consistent by site. The assemblage structure changed significantly between successive

Table 4. Summary of results of permutational multivariate analysis of variance (PERMANOVA) comparing assemblages of fishes over 5 yr (2002 to 2006) at 4 sites in SIMP, and post hoc pairwise comparisons of years at each site. ${ }^{*} p<0.05$,

$$
{ }^{* *} \mathrm{p}<0.01,{ }^{* * *} \mathrm{p}<0.001
$$

\begin{tabular}{|c|c|c|c|c|}
\hline $\begin{array}{l}\text { PERMANOVA } \\
\text { Source }\end{array}$ & df & MS & $F$ & $\mathrm{p}$ \\
\hline Year & 4 & 5146.26 & 2.67 & 0.0004 \\
\hline Site & 3 & 9478.69 & 7.72 & 0.0002 \\
\hline Year $\times$ Site & 12 & 1928.78 & 1.57 & 0.0004 \\
\hline Residual & 140 & 1227.55 & & \\
\hline \multicolumn{5}{|c|}{ Post hoc comparison of years and sites $(t, p)$} \\
\hline Comparison & Site 1 & Site 2 & Site 3 & Site 4 \\
\hline 2002 vs. 2003 & 0.92 & 1.50 & 1.09 & 1.05 \\
\hline 2002 vs. 2004 & 1.49 & 1.48 & 1.37 & 1.11 \\
\hline 2002 vs. 2005 & $2.12^{* *}$ & $1.73^{*}$ & 1.49 & 0.91 \\
\hline 2002 vs. 2006 & 1.07 & 1.42 & 1.10 & 1.00 \\
\hline 2003 vs. 2004 & 1.64 & 1.18 & 1.11 & 0.61 \\
\hline 2003 vs. 2005 & $1.92^{* *}$ & $2.31^{* *}$ & $1.97^{* *}$ & 1.05 \\
\hline 2003 vs. 2006 & 0.99 & $1.74^{*}$ & 1.09 & 1.23 \\
\hline 2004 vs. 2005 & $2.57^{* *}$ & $2.49^{* * *}$ & $1.98^{* *}$ & 1.08 \\
\hline 2004 vs. 2006 & $1.59^{*}$ & $1.64^{*}$ & 1.21 & 1.05 \\
\hline 2005 vs. 2006 & $1.65^{*}$ & $2.11^{* *}$ & $2.07^{* *}$ & 1.06 \\
\hline
\end{tabular}

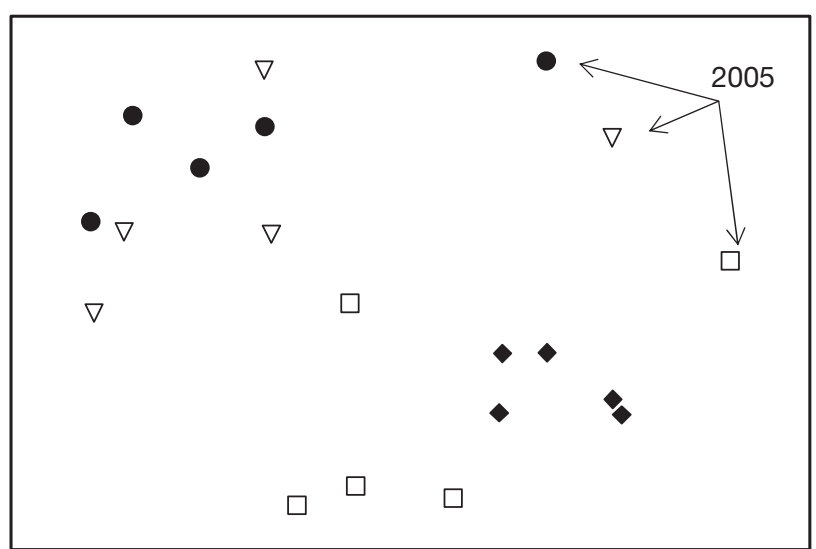

Fig. 6. nMDS plot, based on centroids of 4 sites in the Solitary Islands Marine Park, for each year from 2002 to 2006. Stress = 0.13 (Sites: $\bullet=1 ; \nabla=2 ; \square=3 ; \bullet=4$ )

years at all sites except Site 4 , as shown by the significant Year $\times$ Site interaction (Table 4). Assemblages at Sites 1 to 3 changed dramatically in 2005 compared with previous years and 2006, as shown by the displacement of sample points for these sites to the right of the ordination plot (Fig. 6).

The SIMPER analysis found that no individual species contributed $>3 \%$ to the average dissimilarity of any pairwise comparisons between either years or sites. A combination of 3 to 5 species together contributed $3 \%$ average dissimilarity for both. In comparisons between years this group included the midwater schooling species, Atypichthys strigatus, Trachurus novaezelandiae and Prionurus microlepidotus (Acanthuridae) and Pseudocaranx dentex (Carangidae), and the small benthic schooling hulafish Trachinops taeniatus (Plesiopidae). In 7 out of 10 pairwise comparisons, A. strigatus contributed the highest percentage to this dissimilarity. However, overall >35 species contributed $>1 \%$ dissimilarity for all yearly pairwise comparisons; therefore, univariate analyses were not conducted to examine individual dissimilarity contribution.

Pagrus auratus was examined individually to explore potential underlying reasons for the year by site interaction, as 2 of the sites where there was an obvious

Table 5. Two-factor ANOVA testing for differences in MaxN of Pagrus auratus, between years and sites in SIMP; $\ln (x+1)$ transformed, variance homogeneous (Cochran's test $p>0.05$ ) following transformation

\begin{tabular}{|lrrrc|}
\hline Source & df & MS & $F$ & $p$ \\
\hline Year & 4 & 7.71 & 28.12 & 0.000 \\
Site (Year) & 15 & 0.96 & 3.55 & 0.000 \\
Residual & 160 & 0.27 & & \\
\hline
\end{tabular}




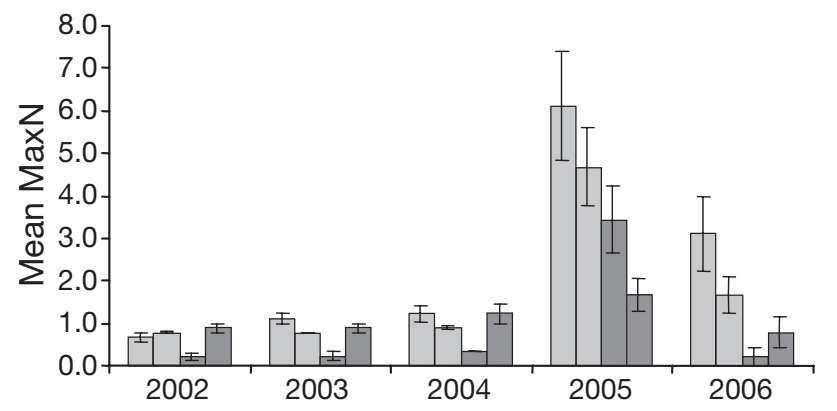

Fig. 7. Pagrus auratus. Mean MaxN $( \pm \mathrm{SE})$ for P. auratus by site (1 to 4 , respectively) and by year (2002 to 2006), in the Solitary Islands Marine Park

change in assemblage in 2005 were in sanctuary zones (Sites 1 and 2). MaxN for $P$. auratus showed a slight increase at Sites 1 and 2 from 2002 to 2004, increased considerably at Sites 1 to 3 in 2005, and then declined in 2006, but remained higher at Sites 1 and 2 in comparison to at Sites 3 and 4 . This reflects the overall pattern detected by PERMANOVA (Table 5, Fig. 7).

\section{DISCUSSION}

As we observed significantly different fish assemblages in all parks, all 3 marine parks are necessary to representatively reserve samples of the reef fish biodiversity in NSW. While the degree of difference in fish assemblages between parks was consistent with the latitudinal gradient, species richness for particular families did not follow any general latitudinal pattern. For instance, Labridae were more diverse in the north, but still diverse with different species in the south, while the Monacanthidae were more strongly represented in the 2 most southern parks. We also found strong temporal stability, over a 5 yr period at SIMP, in the assemblage of reef fish relative to our broader geographic observations.

\section{BRUVS as a technique for sampling reef fish assemblages}

BRUVS is a useful method for comparing and assessing reef fish assemblages on coastal rocky reefs (15 to $30 \mathrm{~m}$ depth) across a range of spatial and temporal scales. With our BRUVS we detected the expected bioregional differences in assemblage structure between 3 widely spaced marine parks, as well as variation at the scale of 2 to $20 \mathrm{~km}$. These scales of spatial variation are similar to those detected by UVC techniques (Curley et al. 2002, Anderson \& Millar 2004) on shallower rocky reef. The significance of spatial variation in the abundance of schooling planktivores for differentiating assemblages detected by our study has also been reported for assemblages of reef fishes described by UVC (Curley et al. 2002).

Although fish bait was used to attract predators and scavengers, a cross-section of the overall reef fish community was sampled, representing a range of trophic guilds including herbivores and planktivores (Appendix 1). This agrees with other BRUVS surveys, where fish attracted to bait or commotion, as well as those passing through or residing in the immediate vicinity, were observed (Cappo et al. 2004, Watson et al. 2005, Stobart et al. 2007). The taxonomic composition of the fish fauna was also similar to that reported from diver surveys from comparable locations in eastern Australia, with Labridae and Monacanthidae being the most speciose families (Parker 1999, Barrett et al. 2006, Gladstone 2007).

BRUVS is a powerful technique for detecting cryptic scavengers. For example, green moray eels Gymnothorax prasinus appear to be more widespread and abundant in the study area than UVC surveys have previously indicated (Curley et al. 2002, Barrett et al. 2006, Gladstone 2007). Although this may be due to UVC surveys being conducted in shallower depths, shallower BRUVS surveys in JBMP suggest this is not the case (J. Wraith unpubl. data). Differences in methods may be more pronounced for cryptic scavengers/ predators that generally reside within the reef matrix, and are unavailable for counting by divers, than for those that rely on camouflage. In SIMP, for example, the cryptic G. prasinus and blindshark Brachaelurus waddi were not recorded from UVC in 10 to $15 \mathrm{~m}$ depth, whereas the well-camouflaged wobbegong shark Orectolobus ornatus was recorded from $14 \%$ of transects (H. Malcolm unpubl. data). By comparison, the same species were recorded in 61, 26 and $33 \%$, respectively, of BRUVS replicates, although in slightly deeper water. Benthic sharks and rays are generally poorly sampled by UVC techniques. Our study recorded 12 species (9 families) of Chondrichthyans. In contrast, an intensive UVC survey of a section of the NSW coast near PSGLMP recorded only 3 species of Chondrichthyans (Gladstone 2007). Trophic transfer through these scavengers/predators on reefs in NSW is poorly understood, but they are likely to be highly important given their abundance and the even distribution revealed in our surveys.

There are a variety of potential issues with the use of BRUVS to describe fish assemblages, which include the sampling requirements to reach species accumulation asymptotes and the influence of factors that vary on a small time scale. Based on our species accumulation curves not reaching asymptote, and from additional species being recorded each year in SIMP, further sampling will detect more species. Fourteen 
species of labrids were recorded over 5 yr of BRUVS surveys in SIMP (Appendix 1). However, a total of 75 species of labrids have been recorded in SIMP (Rule et al. 2007). BRUVS may detect only a proportion of the available labrid diversity, as sets are haphazardly dropped within the small territories of these fish. It is for this reason that, in addition to BRUVS, diver surveys are still warranted to give a more complete picture of reef fish diversity, especially in complex habitats (Watson et al. 2005). Other factors that may bias estimates of abundance include lack of information on the extent of the bait plume and the influence of intraand inter-specific behavioural interactions between fish at the bait. For example, small bits of pilchard dispersed by sharks aggressively feeding on the bait increased the activity of other fishes (authors' pers. obs.), which, in turn, may attract more fish into the viewing area. This inter-specific interaction, regardless of the mechanism involved, may bias samples that contain aggressive feeders, and is an important question for future research. There has been compensation for bait dispersal in other studies by the use of effervescent dissolving baits (Stobart et al. 2007), but pilchards have logistical and comparative advantages in Australia as they are a common bait used in local fisheries and have been used in a number of different studies. Despite these potential issues, this study has shown that when the BRUVS technique is applied in a consistent manner it is able to produce an index that can detect variation in overall fish assemblages.

\section{Spatial variation and latitudinal influences}

Significant variation in assemblages at a range of spatial scales is typical of reef fishes (Curley et al. 2002, Anderson \& Millar 2004, Garcia-Charton et al. 2004, Gladstone 2007). Spatial variation in assemblage structure at large spatial scales may reflect various influences, including biogeography (Edgar et al. 2004), latitude (Bouchon-Navaro et al. 2005), geology (Guidetti et al. 2004), depth, temperature and productivity (Leathwick et al. 2006). At the scale of our NSW marine parks study, the greatest dissimilarity in assemblage structure occurred between the most northern (SIMP) and southern (JBMP) parks, which were separated by $603 \mathrm{~km}$. The middle park, PSGLMP, located halfway between the others, was equally dissimilar to both.

A change in species composition and number was also expected along this latitudinal gradient (Gray 2000); however, similar numbers of total species were recorded in each park (56 to 60 species). There were also differences in higher taxon composition between the parks that did not relate to a latitudinal gradient. For example, twice as many shark and ray species were recorded in PSGLMP than in either SIMP or JBMP, and more species of Monacanthidae were recorded at JBMP and PSGLMP than at SIMP. The species richness of Labridae was bimodal, with peaks at the most northern and southern parks. Combinations of biogeographic, oceanographic and environmental factors are probably responsible for these patterns. For example, the restricted biogeographic distributions for some of the Chondrichthyes endemic to eastern Australia (Last \& Stevens 1994) have influenced the greater species richness observed for this fauna at PSGLMP, by overlapping of subtropical and temperate endemic species (Appendix 1). This overlap may also be reflected in observed family richness, which was greatest in PSGLMP (36) versus SIMP and JBMP (30 and 32, respectively). Australia has more species of Monocanthidae than any other region of the world, with many confined to temperate waters (Randall et al. 1997), and again this biogeographic pattern was reflected in this study. Fish species with a tropi$\mathrm{cal} /$ sub-tropical distribution recorded in SIMP were important in terms of increasing species richness in particular families, and for individual species representation. However, they were less influential than was expected (Meekan \& Choat 1997) in distinguishing the SIMP assemblage from the other parks using this method. Given that the species most important in differentiating between these parks are abundant, and have a distribution that includes all parks (Kuiter 2000), it is possible that assemblage differences could be attributable to large-scale environmental differences that affect populations of many species (Williams 1991).

Significant spatial variation in fish assemblages occurred between sites inside each marine park, i.e. at the scale of kilometres. Spatial variation in assemblage structure of fishes at relatively small spatial scales (100s to 1000 s of metres) may relate to combinations of variation in habitat structure (Connell \& Jones 1991, Willis \& Anderson 2003), recruitment (Connell \& Jones 1991, Lincoln Smith et al. 1991), local hydrodynamics (Warner et al. 2000), or other influences. Although variation at these scales was less than at the betweenpark scale, it indicated some sites (within a park) were more similar than others, and these similarities/differences appeared to be independent of the distance between them, as has been found in other studies (Gladstone 2007).

\section{Temporal variation and stability in patterns}

From the 5 yr of data from SIMP, we consistently sampled a relatively stable fish assemblage of about 30 species with many of the other 58 species rarely 
recorded. This is consistent with the findings of other studies where a large number of the species constitute a small percentage of the number of individuals sampled, and most species are relatively rare (Jones et al. 2002).

The fish assemblage over time was less stable at the site scale, and there was a consistent shift at most of the sites in 2005. Differences between years and sites within SIMP were, like most of our park-wide variation, driven by schooling planktivores, especially Atypichthys strigatus. The difference in 2005 could be due to a range of factors, including environmental conditions, influencing that particular year, or causing short-term variability at a temporal scale not examined, such as weeks. For instance, there was a heavy swell in the weeks preceding sampling in 2005 that may have influenced the assemblage at each site. However, the sampling at Site 1 was repeated 3 wk later with similar results (H. Malcolm unpubl. data). Sea temperature logger records (Malcolm 2007) did not indicate any major differences that would separate 2005 from other years in SIMP, but, given the greatest dissimilarity was due to schooling mid-water planktivores, changes in plankton associated with food resources could have had an influence. If so, this may have been due to localised influences rather than wider processes associated with the El Niño weather pattern. The Southern Oscillation Index (SOI) was close to zero at the time of sampling in 2005, and had generally been in a weak El Niño pattern since mid2004 (NOAA 2007).

There was a distinct increase in abundance of Pagrus auratus at 3 sites in 2005, with changes in other years that closely reflected the overall PERMANOVA pattern. Therefore, the processes that underpinned this increase in $P$. auratus may have also influenced other species. This could have included good recruitment in previous years, as strong inter-annual pulses in snapper recruitment have been demonstrated (Fowler \& Jennings 2003, Hamer \& Jenkins 2004). Marine Park zoning may have also influenced these results as both MaxN and the proportion of sets containing $P$. auratus remained higher at 2 sites in 2006, where fishing has been prohibited since 2002. Again, this is not unexpected as strong benefits of sanctuary zones to snapper populations have been previously demonstrated (Willis et al. 2003, Denny \& Babcock 2004). However, variation in abundance of species such as $P$. auratus can occur within and between years (Willis et al. 2003), and caution is needed in attributing the extent that marine park management has influenced these results. To adequately answer the question of sanctuary zone effectiveness, which was not an aim of the present study, further sampling over a longer time frame is required.

\section{CONCLUSIONS}

Overall, the information provided by BRUVS indicates that the 3 marine parks include different assemblages of fishes on rocky reef at 15 to $30 \mathrm{~m}$ depth. Incorporating natural patterns of variability in assemblages of reef fishes should be a goal of a representative network of marine parks (Lubchenco et al. 2003, Gladstone 2007), and these 3 marine parks contribute towards that goal. Our results also support the existence of bioregions for the fish fauna of shallow coastal reefs in NSW and their use as a basis for MPA planning. However, rocky reef extends down to at least $120 \mathrm{~m}$ depth in NSW, and the spatial patterns of reef fish assemblages below $30 \mathrm{~m}$ are unknown. This study therefore encourages the further application of BRUVS as a technique to investigate the assemblages of fishes in deeper coastal reefs, both inside and outside of marine parks to further examine representation.

BRUVS is also useful for indicating which marine parks are important for representing particular families when used in combination with other methods. As an example of higher taxon representation in marine parks, SIMP may be particularly valuable to conservation of the diversity of Labridae and the southern parks of JBMP and PSGLMP may be important for conservation of the diversity of Monacanthidae. The PSGLMP may also be of importance for conserving the diversity of Chondrichthyes, as this particular rich and abundant chondrichthyan fauna, with a high level of endemism, is unique to rocky reefs in south-eastern Australia (Last \& Stevens 1994).

The present study has demonstrated that BRUVS is a repeatable method that can be used to detect patterns over time at both assemblage and species levels. It, therefore, has application as a monitoring tool, providing sampling is undertaken at suitable multiple temporal and spatial scales that will enable environmental and management influences to be partitioned.

Acknowledgements. Our research was sponsored by the NSW Marine Parks Authority. We thank B. Vercoe, R. Thorman, T. Waters, N. Johnstone, V. Mansbridge, A. Jordan, N. Brown, I. Osterloh and M. Fackerell for assistance in the field. Thanks also to M. Cappo for technical advice, and V. Mansbridge for GIS support. Thanks to A. Jordan, B. Creese and the anonymous reviewers for very helpful comments on an earlier version of this manuscript.

\section{LITERATURE CITED}

Anderson MJ (2001) A new method for non-parametric multivariate analysis of variance. Austral Ecol 26:32-46

Anderson MJ (2003) PCO: a FORTRAN computer program for principal coordinate analysis. Department of Statistics, University of Auckland

Anderson MJ (2005) PERMANOVA: a FORTRAN computer 
program for permutational multivariate analysis of variance. Department of Statistics, University of Auckland

Anderson MJ, Millar RB (2004) Spatial variation and effects of habitat on temperate reef fish assemblages in northeastern New Zealand. J Exp Mar Biol Ecol 305:191-221

ANZECC TFMPA (Australian and New Zealand Environment and Conservation Council, Task Force on Marine Protected Areas) (1998) Guidelines for establishing the national representative system of marine protected areas. Environment Australia, Canberra

ANZECC TFMPA (Australian and New Zealand Environment and Conservation Council, Task Force on Marine Protected Areas) (1999) Strategic plan of action for the national representative system of marine protected areas: a guide for action by Australian governments. Environment Australia, Canberra

Babcock RC, Kelly S, Shears NT, Walker JW, Willis TJ (1999) Changes in community structure in temperate marine reserves. Mar Ecol Prog Ser 189:125-134

Barrett NS (1995) Short- and long-term movement patterns of six temperate reef fishes (families Labridae and Monacanthidae). Mar Freshw Res 46:853-860

Barrett NS, Edgar GJ, Polacheck A, Lynch TP, Clements F (2006) Ecosystem monitoring of subtidal reefs in the Jervis Bay Marine Park. Tasmanian Aquaculture Fisheries Institute, Hobart

Bouchon-Navaro Y, Bouchon C, Louis M, Legendre P (2005) Biogeographic patterns of coastal fish assemblages in the West Indies. J Exp Mar Biol Ecol 315:31-47

Cappo M, Brown I (1996) Evaluation of sampling methods for reef fish populations of commercial and recreational interest. Technical Report No. 6, CRC Reef Research Centre, Townsville

Cappo M, Harvey E, Malcolm H, Speare P (2003) Potential of video techniques to monitor diversity, abundance and size of fish in studies of marine protected areas. In: Beumer JP, Grant A, Smith DC (eds) Aquatic protected areas-What works best and how do we know? Proceedings of the World Congress on Aquatic Protected Areas. Australian Society for Fish Biology, Queensland, p 455-464

Cappo M, Speare P, De'ath G (2004) Comparison of baited remote underwater video stations (BRUVS) and prawn (shrimp) trawls for assessments of fish biodiversity in inter-reefal areas of the Great Barrier Reef Marine Park. J Exp Mar Biol Ecol 302:123-152

Clarke KR (1993) Non-parametric multivariate analyses of changes in community structure. Aust J Ecol 18:117-143

Colwell RK (2005) EstimateS: statistical estimation of species richness and shared species from samples, Version 7.5. Available at: purl.oclc.org/estimates

Connell SD, Jones GP (1991) Influence of habitat structure on post-recruitment processes in a temperate reef fish population. J Exp Mar Biol Ecol 151:271-294

Curley BG, Kingsford MJ, Gillanders BM (2002) Spatial and habitat-related patterns of temperate reef fish assemblages: implications for the design of marine protected areas. Mar Freshw Res 53:1197-1210

Denny CM, Babcock RC (2004) Do partial marine reserves protect reef fish assemblages? Biol Conserv 116:119-129

Edgar GJ, Barrett NS (1999) Effects of the declaration of marine reserves on Tasmanian reef fishes, invertebrates and plants. J Exp Mar Biol Ecol 242:107-144

Edgar GJ, Banks S, Farina JM, Calvopina M, Martinez C (2004) Regional biogeography of shallow reef fish and macro-invertebrate communities in the Galapagos archipelago. J Biogeogr 31:1107-1124
Ellis DM, DeMartini EE (1995) Evaluation of a video camera technique for indexing abundances of juvenile pink snapper, Pristipomoides filamentosus and other Hawaiian insular shelf fishes. Fish Bull 93:67-77

Ferrier S (2002) Mapping spatial pattern in biodiversity for regional conservation planning: Where to from here? Syst Biol 51:331-363

Fowler AJ, Jennings PR (2003) Dynamics of 0+ recruitment and early life history for snapper (Pagrus auratus, Sparidae) in South Australia. Mar Freshw Res 54:941-956

Garcia-Charton JA, Perez-Ruzafa A, Sanchez-Jerez P, BayleSempere JT, Renones O, Moreno D (2004) Multi-scale spatial heterogeneity, habitat structure, and the effect of marine reserves on western Mediterranean rocky reef fish assemblages. Mar Biol 144:161-182

Gladstone W (2007) Requirements for marine protected areas to conserve the biodiversity of rocky reef fishes. Aquat Conserv 17:71-87

Gray JB (2000) The measurement of marine species diversity, with an application to the benthic fauna of the Norwegian continental shelf. J Exp Mar Biol Ecol 250:23-49

Guidetti P, Bianchi CN, Chiantore M, Schiaparelli S, Morri C, Cattaneo-Vietti R (2004) Living on the rocks: substrate mineralogy and the structure of subtidal rocky substrate communities in the Mediterranean Sea. Mar Ecol Prog Ser 274:57-68

Hamer PA, Jenkins GP (2004) High levels of spatial and temporal recruitment variability in the temperate sparid Pagrus auratus. Mar Freshw Res 55:663-673

Henry GW, Lyle JM (2003) The national recreational and indigenous fishing survey. FDRC Project No 99/158, Tasmanian Aquaculture Fisheries Institute, Hobart

Jablonski D, Sepkoski JJ Jr (1996) Paleobiology, community ecology, and scales of ecological pattern. Ecology 77: $1367-1378$

Jones GP, Caley MJ, Munday PL (2002) Rarity in coral reef fish communities. In: Sale PF (ed) Coral reef fishes: dynamics and diversity in a complex ecosystem. Academic Press, New York, p 81-102

Kuiter RH (2000) Coastal fishes of south-eastern Australia. Gary Allen Pty Ltd, Sydney

Last PR, Stevens JD (1994) Sharks and rays of Australia. CSIRO, Melbourne

Leathwick JR, Elith J, Francis MP, Hastie T, Taylor P (2006) Variation in demersal fish species richness in the oceans surrounding New Zealand: an analysis using boosted regression trees. Mar Ecol Prog Ser 321:267-281

Lincoln Smith MP, Bell JD, Hair CA (1991) Spatial variation in abundance of recently settled rocky reef fish in southeastern Australia: implications for detecting change. Mar Ecol Prog Ser 77:95-103

Lubchenco J, Palumbi SR, Gaines SD, Andelman S (2003) Plugging a hole in the ocean: the emerging science of marine reserves. Ecol Appl 13(Suppl):3-7

Malcolm HA (2007) Expansion of a sea temperature monitoring program in the NRCMA area. In: Sustainable marine resource management project, Part A: research, mapping, assessment and planning. Report to the Northern Rivers Catchment Management Authority. National Marine Science Centre, Coffs Harbour

Margules CR, Pressey RL (2000) Systematic conservation planning. Nature 405:243-253

Meekan MG, Choat JH (1997) Latitudinal variation in abundance of herbivorous fishes: a comparison of temperate and tropical reefs. Mar Biol 128:373-383

NOAA (National Oceanic and Atmospheric Administration) (2007) Climate of 2005 El Niño/Southern Oscillation 
(ENSO). Available at: www.ncdc.noaa.gov/climate/ research/2005/ann/enso-monitoring.html

NSW Marine Parks Authority (2006) Status Report 2004-2005. Available at: www.mpa.nsw.gov.au

Parker PG (1999) Fish assemblages at Julian Rocks and the adjacent waters of northern New South Wales, Australia. Aust Zool 31:134-160

Randall JE, Allen GR, Steene RC (1997) The complete divers' \& fishermen's guide to fishes of the Great Barrier Reef and Coral Sea. Crawford House Publishing, Bathurst

Rule M, Jordan A, McIlgorm A (2007) The marine environment of northern New South Wales. A review of current knowledge and existing datasets. Report to the Northern Rivers Catchment Management Authority. National Marine Science Centre, Coffs Harbour

Stobart B, Garcia-Charton JA, Espejo C, Rochel E and 8 others (2007) A baited underwater video technique to assess shallow-water Mediterranean fish assemblages: methodological evaluation. J Exp Mar Biol Ecol 345:158-174

Terlizzi A, Benedetti-Cecchi L, Bevilacqua S, Fraschetti S, Guidetti P, Anderson MJ (2005) Multivariate and univariate asymmetrical analyses in environmental impact assessment: a case study of Mediterranean subtidal sessile assemblages. Mar Ecol Prog Ser 289:27-42

Underwood AJ (1981) Techniques of analysis of variance in experimental marine biology and ecology. Oceanogr Mar Biol Annu Rev 19:513-605

Underwood AJ (1997) Ecological experiments: their logical design and interpretation using analysis of variance. Cambridge University Press, Cambridge

Underwood AJ, Chapman MG, Connell SD (2000) Observations in ecology: you can't make progress on processes without understanding the patterns. J Exp Mar Biol Ecol 250:97-115

Warner RR, Swearer SE, Caselle JE (2000) Larval accumulation and retention: implications for the design of marine reserves and essential fish habitat. Bull Mar Sci 66:821-830

Watson DL, Harvey ES, Anderson MJ, Kendrick GA (2005) A comparison of temperate reef fish assemblages recorded by three underwater stereo-video techniques. Mar Biol 148:415-425

Westera M, Lavery P, Hyndes G (2003) Differences in recreationally targeted fishes between protected and fished areas of a coral reef marine park. J Exp Mar Biol Ecol 294:145-168

Williams DM (1991) Patterns and processes in the distribution of coral reef fishes. In: Sale PF (ed) The ecology of fishes on coral reefs. Academic Press, New York, p 437-474

Willis TJ, Anderson MJ (2003) Structure of cryptic reef fish assemblages: relationships with habitat characteristics and predator density. Mar Ecol Prog Ser 257:209-221

Willis TJ, Millar RB, Babcock RC (2000) Detection of spatial variability in relative density of fishes: comparison of visual census, angling, and baited underwater video. Mar Ecol Prog Ser 198:249-260

Willis TJ, Millar RB, Babcock RC (2003) Protection of exploited fish in temperate regions: high density and biomass of snapper Pagrus auratus (Sparidae) in northern New Zealand marine reserves. J Appl Ecol 40:214-227

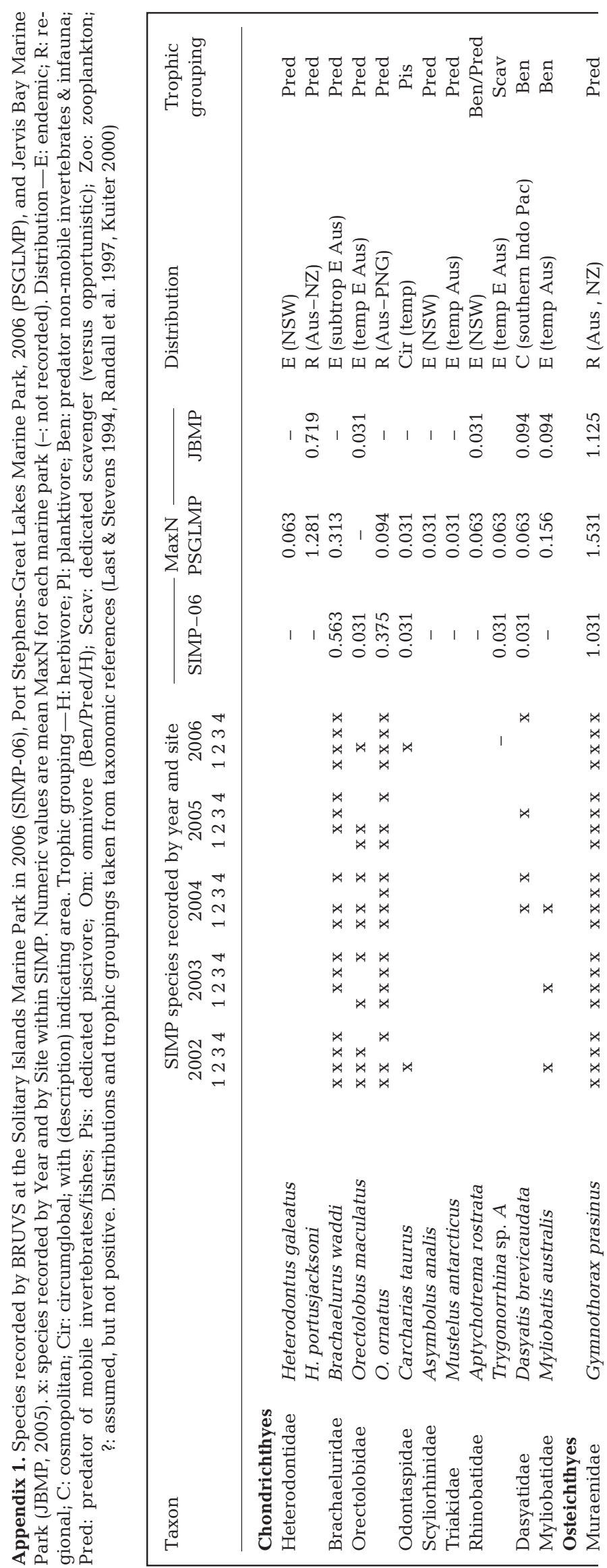




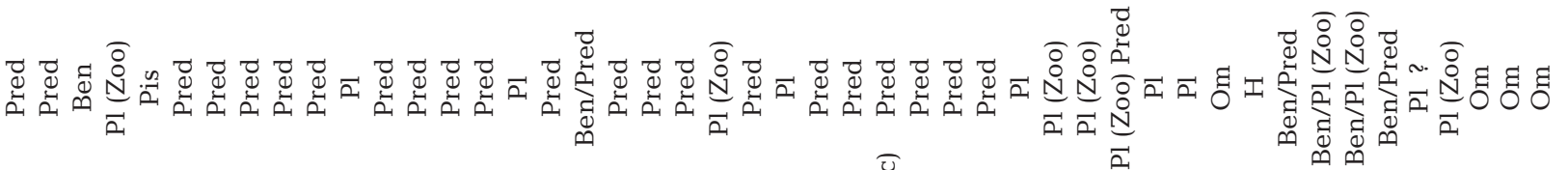

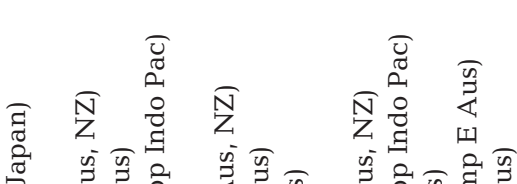

$$
\bar{\nabla} \quad \vec{a}
$$

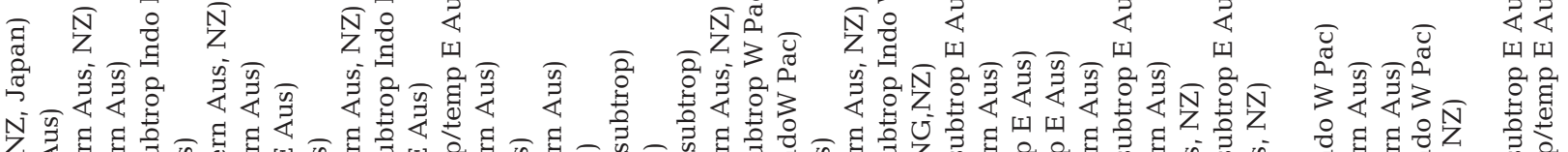

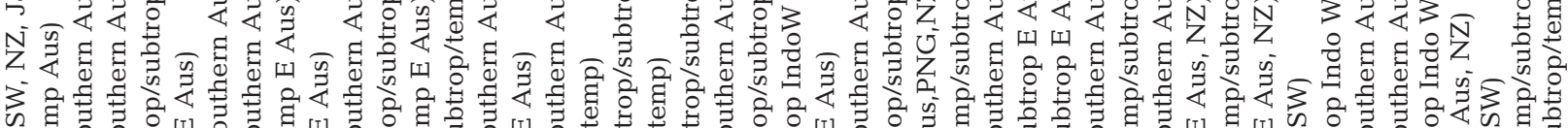

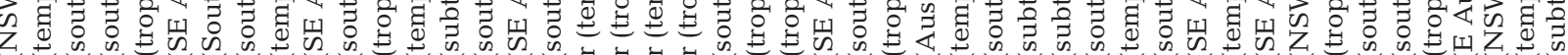

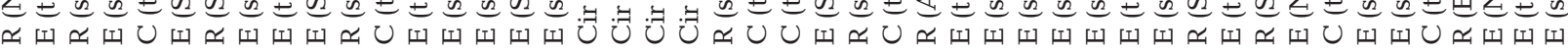

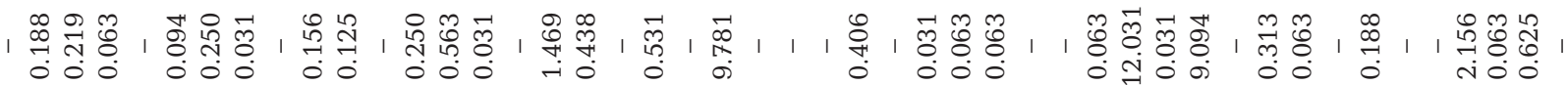

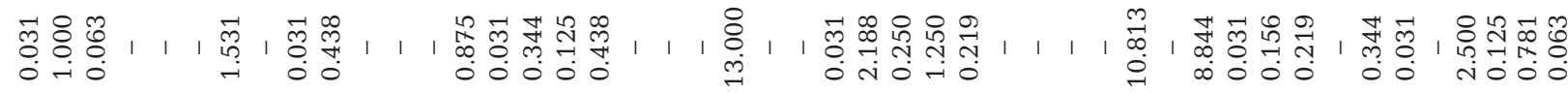

\begin{tabular}{|c|c|c|c|c|c|c|c|c|c|c|c|}
\hline & $\begin{aligned} x \\
\times \\
x \\
x \\
x \\
x\end{aligned}$ & $\begin{array}{l}x \\
x \\
x \\
x \\
x\end{array}$ & 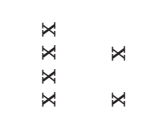 & $\stackrel{\underset{x}{x}}{\underset{x}{\times} \times}$ & 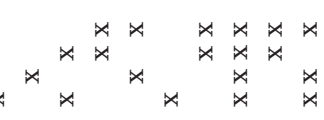 & $\star \star$ & 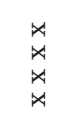 & $\begin{array}{l}\underset{x}{x} \\
x \\
x \\
x\end{array}$ & & $\not$ & ${ }^{\star} \star$ \\
\hline${ }^{\star}$ & $\begin{array}{l}\underset{x}{x} \\
\times \\
x \\
x\end{array}$ & $\begin{array}{l}\underset{x}{x} \\
\stackrel{x}{x} \\
\underset{x}{\not}\end{array}$ & 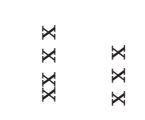 & $\begin{array}{l}\underset{x}{\times} \\
\stackrel{x}{x} \\
\stackrel{x}{x}\end{array}$ & 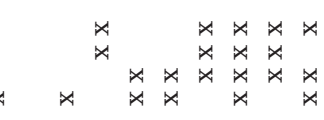 & & 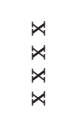 & $\begin{array}{l}\underset{x}{x} \\
x \\
x \\
x\end{array}$ & & 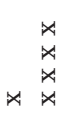 & $\stackrel{x}{x}$ \\
\hline & $\begin{array}{l}\not \\
\otimes \\
x \\
\propto\end{array}$ & $\begin{array}{l}x \\
x \\
x \\
x \\
x\end{array}$ & 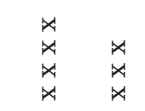 & $\star$ & 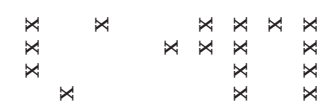 & $\star$ & $\underset{x}{\stackrel{x}{x}}$ & $\begin{array}{l}\underset{x}{x} \\
x \\
x \\
x\end{array}$ & & $\star$ & $\underset{x}{x}$ \\
\hline & $\underset{\substack{x \\
x \\
\dot{x} \\
\dot{x}}}{x}$ & 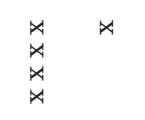 & $\begin{array}{l}\underset{x}{\infty} \\
\infty \\
x \\
x\end{array}$ & $\stackrel{x}{x}$ & 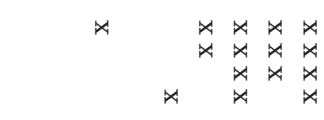 & & $\underset{x}{x}$ & $\begin{array}{l}\underset{x}{x} \\
\stackrel{x}{x} \\
\stackrel{x}{x}\end{array}$ & & & $\star$ \\
\hline & $\begin{array}{l}\underset{x}{x} \\
\underset{x}{x}\end{array}$ & $\begin{array}{l}\stackrel{x}{x} \\
\stackrel{x}{\times} \\
\stackrel{x}{x}\end{array}$ & $\begin{array}{l}\stackrel{x}{\times} \\
\stackrel{x}{\times} \\
\stackrel{x}{x}\end{array}$ & & 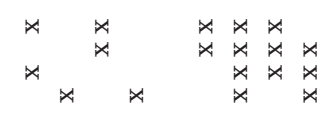 & $\star \star x$ & $\underset{\underset{x}{x}}{\stackrel{x}{x}}$ & $\stackrel{x}{x}_{\stackrel{x}{x}}$ & & $\begin{array}{l}\star x \\
\stackrel{x}{x}\end{array}$ & ${ }^{\star}$ \\
\hline
\end{tabular}

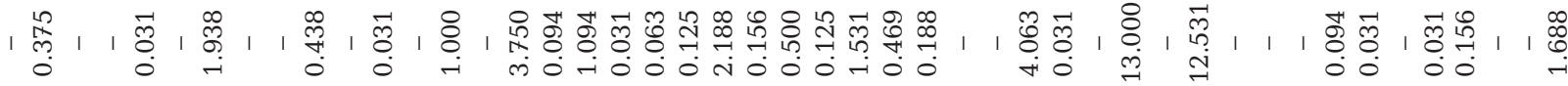

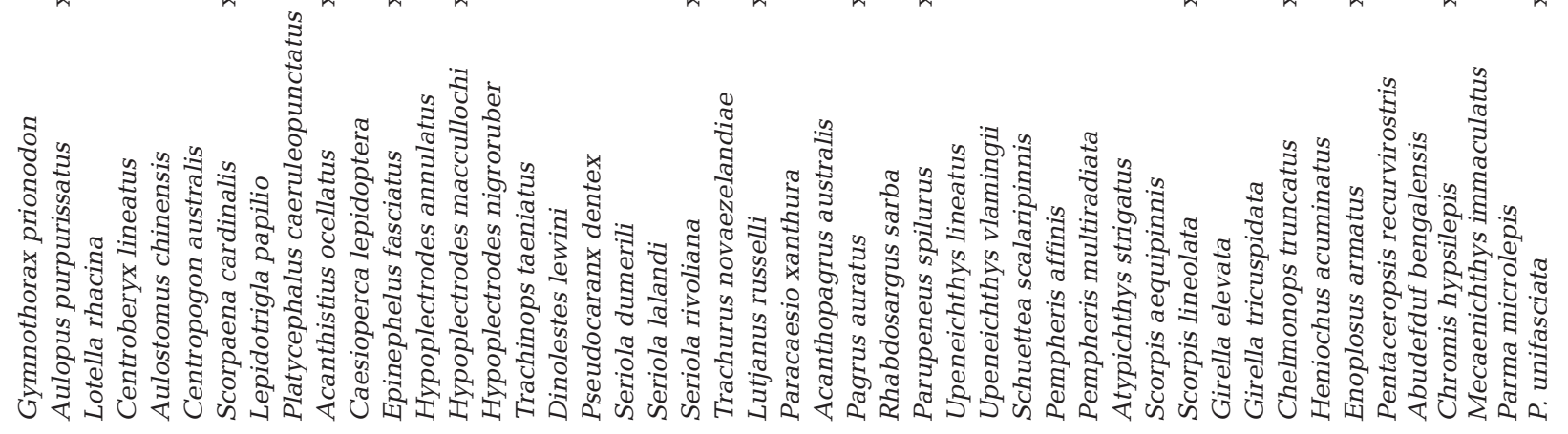




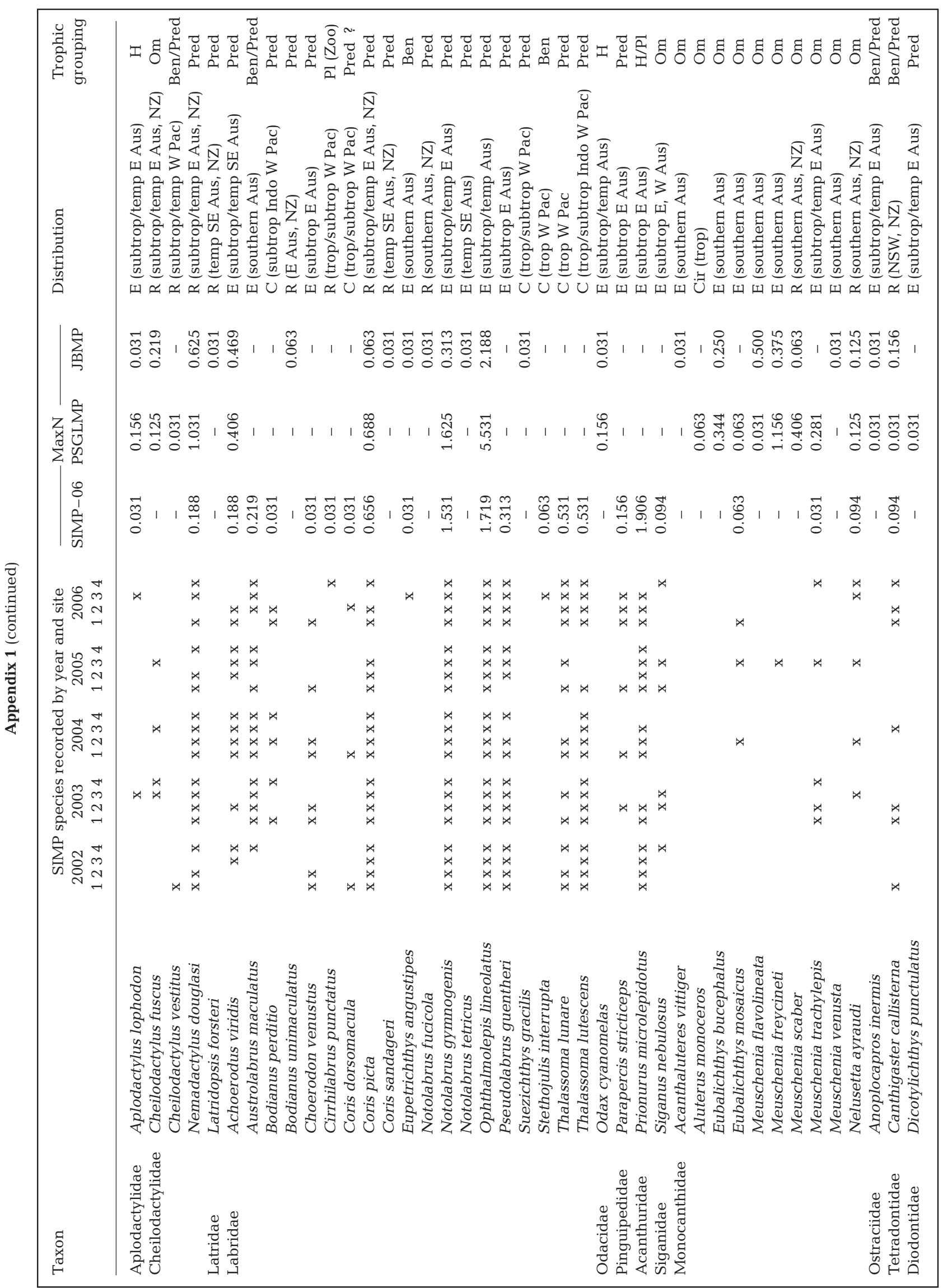

